\title{
Preserving the nation's intellectual heritage: A synthesis
}

By Sherry Byrne and Barbara Van Deventer

\section{Microfilming alone will not solve all preservation problems}

$\mathbf{T}$ his document represents the authors' perspectives gained from working in research libraries engaged in large-scale preservation programs. It concisely charts the historical developments in preservation, characterizes the current situation, and identifies directions for the future.

These ideas evolved out of several informal discussions among preservation officers and heads of collection development about preservation issues facing large research libraries. By sharing this effort with a wider audience, we hope that these ideas will promote awareness and assist those developing their own preservation programs.

The authors wish to acknowledge their colleagues in the following libraries who participated in these discussions: Columbia University, Comell University, Harvard University, the New York Public Library, Northwestern University, Stanford University, University of California-Berkeley, University of Chicago, University of Michigan, University of Texas at Austin, and Yale University.

\section{History}

Concern about the deterioration of the nation's research and scholarly works is not new. The Council on Library Resources (CLR) is one of the earliest supporters of preservation activities. These actions on the part of CLR began in the 1950s. In the early 1960s the Association of Research Libraries (ARL) began an active program on book deterioration. In 1966 a report by Gordon Williams was issued on the deterioration of paper in American libraries. In 1972 ARL and the Office of Education supported a study conducted by Warren J. Haas. This study was the first articulation of plans for a national preservation program.

In 1984 the ARL membership passed a resolution urging CLR to define a national strategy for preservation. A Committee on Preservation was formed and charged with creating a man-

Access to what is preserved is as important as the preservation of the information itself ...

agement structure, defining a funding plan, and setting the characteristics of and conditions for a national program.

Two key conclusions were reached after 18 months of study that would shape the establishment of a national program. Access to what is preserved is as important as the preservation of the information itself, and books would receive first priority in planning for a nationwide program. This meant a single focus on preserving the intellectual content of books through the use of microfilm, an effective technology and medium that is suitable for making copies of works so that they can be easily accessible.

In early 1986 the Committee on Preservation and Access published Brittle Books, a highly 
influential plan for making a national preservation program a reality. It recommended that a Commission on Preservation and Access be formed and supported by universities and foundations. The commission was to hire staff and pursue the work plans outlined in Brittle Books. The commission first met in April 1986 and it became an independent nonprofit organization in 1988.

The commission carried forward the assumptions of the earlier committee's work. In defining a national preservation program "the ultimate goal is to create an accessible national collection of preserved materials. It is not to reconstitute the present collection of every library." This would involve the development of a nationwide, collaborative, large-scale filming program to capture the intellectual content of brittle books.

Called the Brittle Books Program, it was estimated that of the 78 million brittle books in the nation's libraries, about 68 million of them are duplicates. Thus it was considered that of the 10 million remaining, about 3 million represent "the essential core collection to be saved." To accomplish this national strategy, 20 strong research libraries would need to be involved in a 20 -year filming project. The commission also hoped that a central distribution service could be created where master copies would be held for copying and distribution.

In 1989 the initial phase of this program was supported by Congress authorizing enhanced funding for the National Endowment for the Humanities Office of Preservation. By bringing

\section{Columbia's conservation program moves}

The conservation Education Programs of the School of Library Service at Columbia University will join the Graduate School of Library and Information Science (GSLIS) at the University of Texas at Austin effective July 1992 . The program was forced to look for a new home when, in June 1990, the trustees of Columbia University voted to phase out the School of Library Service. Brooke E. Sheldon, dean of the GSLIS, said, "We are absolutely elated that the ... Conservation Education Programs ... will find a new home at UT Austin." this microfilming initiative under the auspices and funding of NEH's Office of Preservation, the assumption was that the appropriate subject areas to be preserved would be in the humanities as broadly defined by NEH. In return for accepting federal funding, participating institutions would agree to certain reformatting and bibliographic control standards and the provision of access. Archival masters would be stored in a climate-controlled, secure facility.

\section{Present situation}

Three-and-a-half fiscal years of enhanced funding for the recently designated NEH Division of Preservation and Access have now passed (1989-1991) with grants awarded to 49 librar ies and library consortia and approximately 450,000 volumes of books and serials not previously preserved being reformatted to microfilm. Selection of materials to be preserved through these grants relied for the most part on the distinguished subject collections concept. These significant accomplishments were realized in a short period of time because of the initiative and focus of the Commission on Preservation and Access and the NEH Division of Preservation and Access.

This has been an evolving process and libraries participating in the program have undergone an intensive learning experience. The knowledge gained from managing these grants involving substantial reformatting to microfilm has also caused new issues to emerge.

It has become evident that the definition of "brittleness"- the fragility of paper due to acid deterioration-encompasses a variation along a continuum from being able to turn a page several times before breaking to the extreme whete a page will break off when turned only once. Therefore, not all brittle materials are equally deteriorated. This allows us to consider a wider range of factors that influence the selection of materials for preservation.

- Usability of texts rather than a narrow definition of brittleness is the important selection concept. Usability measures incorporate such elements as the method of leaf attachment and the condition of the cover in conjunction with brittleness.

- Within this concept time has been gained, thus allowing libraries to focus attention on materials most at risk of loss and delay the treatment of others. This provides flexibility for institutions engaging in preservation activities. 
- Many early grants before the large-scale microfilming program was articulated involved disbinding texts to be filmed and then discarding the works. Now projects include the option of filming volumes intact in book cradles for about the same costs as for disbinding. This means that works can be retumed to the shelf for continued use if that is considered desirable.

- The primacy of a subject-based approach to preserve the nation's three-million-book core collection does not address the books constituting important research interests that are identified for preservation through use. Both approaches should be considered complementary selection strategies.

- While we have had great success in funding preservation grants in the humanities, it would be beneficial to expand federal guidelines to include funding for non-historical subjects in the social sciences and sciences

- Microfilming is only one of the broad range of preservation choices that can address the variety of problems represented by the nation's deteriorating collections.

- Planned redundancy is a desirable element in a strategy to preserve the nation's resources. Institutions and the nation may benefit from selection of different preservation options for the same title as a way of meeting the needs of scholarship across time and distance.

- Institutions are making an investment by preserving their collections. The nation gains by this investment and should, therefore, carry a greater portion of the cost. Institutions, because of cost-share requirements by U.S. federal funding agencies, carry too much of the burden. This obligation can also divert funds from other local preservation priorities.

\section{Future}

This experience has brought libraries to the realization that the preservation of our national heritage is a complex undertaking. Time has been a major factor enabling us to understand where we have been, what preservation issues are of importance, and what some of the critical new directions should be for the future.

The importance of microfilming as a central means of preserving our libraries' collections has been and continues to be demonstrated. The leadership of the commission must be acknowledged in this monumental effort. However, many libraries now believe that they must move beyond the assumption that an acces- sible national collection of preserved materials can be accomplished through a microfilming program alone

The purpose of preservation services in libraries is to maintain access to information threatened by deterioration. Maintenance of access means assuring the continued existence of a version of the text or information. Libraries have a range of preservation problems that point toward the need for a variety of solutions to adequately meet the requirements of library users. Preservation experience has led to the conclusion that a comprehensive approach to preserving the nation's deteriorating collections is needed.

\section{However, many libraries now}

believe that they must move

beyond the assumption that an

accessible national collection of

preserved materials can be

accomplisbed through a micro-

filming program alone.

A comprehensive program would maintain the integrity of the nation's collections by keeping needed copies of materials available in a given location, select for preservation the materials most at risk, and use a full range of methods to provide appropriate preservation solutions. The methods include repair, restoration, mass deacidification, boxing, photocopying, microfilming, and purchase of commercial reprint and microform replacements. NEH has already begun to respond to these broader issues by allowing repair activities to be incorporated into library preservation microfilming projects, either with direct project funds or as cost-share responsibility.

The worry about an apparent dichotomy between the national microfilming program and local comprehensive preservation needs may take on a more benign cast if we consider that these two approaches can serve as a complement to one another in the context of larger preservation concerns. Viewed this way, neither should displace the other or compete unnecessarily for funds. Instead, the national preservation program becomes a comprehensive one with microfilming as one important element among many. 


\section{Keep Your Library Up to Date With These Important Publications!}

\section{BRITISH UNIVERSITY LIBRARIES}

\section{Dr. Toby Burrows}

University of Western Australia

"This highly informed analysis of their present condition by an Australian librarian shows the radical changes in the nature of the universities and their purpose, and the grievous changes in their libraries that have resulted. Required read. ing for American academic librarians, since in many ways it depicts our future 20 years hence." -Ellsworth Mason, PhD, Private Consultant, Lexington, Kentucky

\$29.95 hard. ISBN: 0-86656-917-0. 1989.

\section{A CHANGING WORLD}

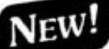

Proceedings of the 6 th North American

Serials Interest Group, Inc.

Edited by Suzanne McMahon, MIS

Serials Cataloger, Green Library, Stanford University

Miriam Palm, MLS

Principal Acquisitions Librarian, Stanford University

Pamela Dunn, BA

Library Specialist, Stanford University, California

Authoritative contributors provide insight, inspirations, and practical experience to the three major areas of changing technologies, changing information worldwide, and strategies and responses of libraries to these rapid changes.

(A monograph published simultaneously as

The Serials Librarian, Vol. 21, Nos. 2/3.)

$\$ 24.95$ hard. ISBN: 1-56024-263-9.

$\$ 9.95$ soft. ISBN: 1-56024-278-7. 1992. Available now.

\section{SERIALS INFORMATION}

From Publisher to User

Practice, Programs, and Progress

Proceedings of the 3rd North American

Serials Interest Group, Inc.

Edited by Leigh A. Chatterton, MLS

Co-Chair, Program and Publications Committees, NASIG

Mary Elizabeth Clack, MIS

Serial Records Librarian, Harvard College Library

By exploring the relationships among the librarian, publisher, and vendor, this book builds a better understanding of these three positions. Discussions include the economics of journal publishing, the challenge of cataloging computer files, and the current developments in the bibliographic control of serials.

(A monograph published simultaneously as

The Serials Librarian, Vol. 15, Nos. 3/4.)

$\$ 22.95$ hard. ISBN: 0-86656-894-8, 1988.

\section{THE FUTURE OF SERIAIS}

Proceedings of the North American

Serials Interest Group, Inc.

Edited by Patricia Ohl Rice, MIS, PhD

Documentation and Training Librarian, Pennsylvania State University

Jane A. Robilland, MIS

Medical Librarian, Veteran's Administration Medical Center, Perry Point, Maryland

Brings together 33 in-depth chapters to keep you aware of current issues in serials publishing and management, including a variety of issues such as rising prices, collections weeding, and automated management.

(A monograph published simultaneously as

The Serials Librarian, Vol. 19, Nos. 3/4.)

$\$ 29.95$ hard. ISBN 1-56024-081-4. 1991.

\section{THE SERIAIS PARTNERSHIP}

Teamwork, Technology, and Trends

Proceedings of the North American

Serials Interest Group, Inc.

Edited by Patricia Ohl Rice, MLS, PhD

Documentation and Training Librarian, Pennsylvania State University

Joyce L. Ogburn, MSIS, MA

Medical Librarian, Veteran's Administration Medical Center, Perry Point, Maryland

Lively and informative, this volume addresses several highly important topics, including scholarly communication, CD-ROM, types of serials vendors and whether a library should use a single vendor, and organizational and institutional concerns about the journal pricing. (A monograph published simultaneously as The Serials Librarian, Vol. 17, Nos. 3/4.) \$34.95 hard. ISBN: 0-86656-991-X. 1990.

\section{THE SERIAIS INFORMATION CHAIN}

Discussion, Debate, and Dialog

Proceedings of the North American

Serials Interest Group, Inc.

Edited by Leigh Chatterton, MIS

Co-Chair, Program and Publications Committees, NASIG

Mary Elizabeth Clack, MLS

Serial Records Librarian, Harvard College Library

The essays are uniformly lively and provide excellent overvieus of the aspects of serials control, from acquisition to automation"

-Academic Library Book Review

(A monograph published simultaneously as

The Serials Libraries, Vol. 11, Nos. 3/4.)

$\$ 34.95$ hard. ISBN: 0-86656-6546. 1987.

NASIG Members: 50\% Off on NASIG Proceedings.

CALL OUR TOLL-FREE NUMBER: 1-800-3-HAWORTH 1-800-342.9678/US orders ony / 9am-5pm EST 